\title{
Nipple-preserving total glandectomy for noninvasive breast carcinoma
}

\section{ORIGINAL ARTICLE Annals of Cancer Research and Therapy}

\author{
Shoji Oura - Takeo Sakurai · Goro Yoshimura - Takesi Tamaki · \\ Teiji Umemura, Yozo Kokawa*
}

\begin{abstract}
Between January 1978 and March 1995, 37 patients with noninvasive breast carcinoma (excluding Paget's disease) were treated at our department. Out of the 37 patients, 20 were treated with nipple-preserving total glandectomy. Eighteen had noninvasive ductal carcinoma and two had lobular carcinoma in situ. All eighteen noninvasive ductal carcinomas were of the non-comedo type. Nineteen patients received nipple-preserving total glandectomy and axillary dissection. One patient was initially treated with microdochectomy, and then additional nipple-preserving total glandectomy and axillary dissection were done to remove positive margins. All patients received tamoxifen as adjuvant therapy, but no adjuvant radiotherapy was given. These 20 patients had no cancer infiltration of the nipple base and all remain alive without disease after 63 months on the average.

In conclusion, breast surgeons should always take nipple-preserving total glandectomy into consideration for patients with noninvasive breast cancer.

Ann Cancer Res Ther 5(1) : 25 28, 1996/Received 6 Mar 1996, Accepted 17 Apr 1996 Key words : nipple-preserving total glandectomy, noninvasive breast carcinoma, nipple base resection, thick flap technique
\end{abstract}

Both noninvasive ductal carcinoma and lobular carcinoma in situ tend to spread widely in the mammary gland $^{1 \sim 4)}$. Therefore, many breast surgeons consider that noninvasive breast carcinoma should not be treated with breast-conserving therapy, and they are likely to choose mastectomy for noninvasive carcinoma ${ }^{7,8}$. The present study retrospectively investigated the surgical results of nipple-preserving total glandectomy for noninvasive breast carcinoma, and evaluated the clinical role of this procedure.

\section{Patients and methods}

Between January 1978 and March 1995, 37 patients with noninvasive breast carcinoma (excluding Paget's disease) were treated at our department. Twenty of the 37 patients underwent nipple-preserving total glandectomy, 10 with breast-conserving surgery and seven with mastectomy. These 20 patients receiving nipple-preserving total glandectomy were enrolled in our study (Table 1).

Of the 20 patients, 13 were diagnosed by excisional biopsy, three by aspiration biopsy cytology, one by frozen section, one by microdochectomy, and the other two from nipple discharge showing highly elevated CEA levels and containing malignant cells. Eighteen patients had

\footnotetext{
* The Department of Surgery, Kihoku Hospital, Wakayama Medical College

Correspondence to : Shoji Oura, The Department of Surgery, Kihoku Hospital, Wakayama Medical College, 219 Myoji, Katsuragi-cho, Itogun, Wakayama 649-71, Japan. TEL 0736-22-0066. FAX0736-22-2579
}

noninvasive ductal carcinoma and two had lobular carcinoma in situ. There was one patient with simultaneous bilateral noninvasive ductal carcinoma (case 2). All 18 noninvasive ductal carcinomas were of the non-comedo type. There were five $\mathrm{T} 0$ breast carcinomas. Three of these five T0 tumors were detected by microcalcification on mammograms and two by bloody nipple discharge. Three of the 15 palpable noninvasive breast carcinomas were associated with bloody nipple discharge.

Out of the 20 patients, 19 were treated with nipplepreserving total glandectomy and axillary dissection $\left(\mathrm{Glt}+\mathrm{Ax}^{9)}\right)$. One was initially treated with microdochectomy, and then underwent additional nipplepreserving total glandectomy and axillary dissection to remove positive margins. All patients received tamoxifen as adjuvant therapy, but none of them received adjuvant radiotherapy. We examined the largest cut surface for the palpable tumors, the focus containing microcalcification for T0 cases with such microcalcification or whole mammary gland sections for T0 cases with bloody nipple discharge. Except in patients with T0 breast carcinoma discovered because of bloody nipple discharge, we routinely checked the tissue in the lactiferous sinuses and the skin just above the tumor (if skin was resected).

\section{Results}

(1) Margin positivity

No patient had cancer infiltration of the nipple base. The microdochectomized patient had cancer infiltraion 
Table1 Noninvasive breast carcinomas treated with nipple preserving total glandectomy

\begin{tabular}{|c|c|c|c|c|c|c|}
\hline No. & Age & $\mathbf{T}(\mathrm{cm})$ & $\mathbf{n}$ & $\mathbf{D}(\mathbf{c m})$ & Histology & Outcome \\
\hline 1. & 40 & T0 & no & $?$ & la(pap/crib) & 4GM NED \\
\hline 2. & 77 & 2.082 .0 & no & $?$ & la(papillary) & 39M NED \\
\hline 3. & 50 & 2.5 & no & $\mathbf{0}$ & 1a(pap/crib) & 34M NED \\
\hline 4. & 64 & 2.1 & no & 0.7 & la(papillary) & 19M NED \\
\hline 5. & 41 & 1.0 & n0 & 3.3 & $1 a($ pap/crib) & 170M NED \\
\hline 6. & 39 & 2.3 & no & $\mathbf{0}$ & 1a(intracystic;pap/crib) & 44M NED \\
\hline 7. & 48 & T0 & no & $?$ & 1a(low papillary) & 29M NED \\
\hline 8. & 63 & 2.0 & no & 3 & 1a(pap-tub.) & 174M NED \\
\hline 9. & 45 & 2.0 & no & 4.5 & 1a(pap-tub.) & 141M NED \\
\hline 10. & 43 & 2.0 & no & 3 & 1a(pap-tub.) & 131M NED \\
\hline 11. & 42 & 1.8 & no & 4.6 & 1a(papillary) & 76M NED \\
\hline 12. & 42 & 1.6 & no & 2.2 & la(papillary) & 74M NED \\
\hline 13. & 48 & 3.0 & no & 0.3 & 1a(papillary) & 28M NED \\
\hline 14. & 40 & T0 & no & $?$ & la(pap/crib) & 64M NED \\
\hline 15. & 48 & 2.0 & no & 1.5 & la(pap/crib) & 45M NED \\
\hline 16. & 68 & 1.8 & no & 1 & la(solid,papillary) & 15M NED \\
\hline 17. & 41 & 1.5 & no & 2.3 & $1 \mathrm{~b}$ & 72M NED \\
\hline 18. & 52 & 3.7 & no & $\mathbf{0}$ & 1b & 39M NED \\
\hline 19. & 41 & To & no & $?$ & 1a(papillary) & 9M NED \\
\hline 20. & 44 & To & no & $?$ & la(papillary) & 9M NED \\
\hline
\end{tabular}

la : noninvasive ductal carcinoma. Ib : lobular carcinoma in situ pap/crib : papillary-cribriform. pap-tub. : papillotubular.

$\mathrm{M}$ : months. NED : no evidence of disease. $\mathrm{D}$ : tumor-areolar distance

only in the lateral stumps and had no infiltration of the nipple base. No patient had cancer infiltration of the skin or the subcutaneous fat.

\section{(2) Axillary node involvement (Table 1)}

All patients underwent axillary dissection ; five underwent dissection only to level 1 and the other 15 had dissection up to the high axilla (i.e level 3). No patient had axillary metastasis.

(3) Clinical outcome (Table 1)

All of the patients have survived for $9 \sim 174$ months (mean: 63 months) without recurrence.

\section{Discussion}

Noninvasive ductal carcinoma tends to spread extensively in the mammary ducts, while lobular carcinoma in situ is often multicentric ${ }^{1 \sim 4}$. However the prognosis is neither influenced by the presence or the extent of the intraductal component, nor by the presence and number of multiple foci provided that the carcinoma is really noninvasive and is treated with mastectomy. At least, extensive intraductal component (EIC) and multicentricity are independent of the staging system used by the Japanese Breast Cancer Society or the UICC.

It is well known that EIC is the most important pathologic risk factor ${ }^{10-15)}$ in breast-conserving therapy (BCT). Oncologists with the opinion that BCT is essentially radiotherapy and that surgery is an adjuvant for radiotherapy often ignore the presence or extent of EIC at the surgical margin. Nevertheless, it is still controversial whether radiotherapy is effective for EIC or not ${ }^{16,17)}$. In addition, many authors have reported a close relationship between the presence of EIC and local recurrence ${ }^{11-15)}$.

On the other hand, it is still difficult to predict the extent of EIC exactly ${ }^{5,6)}$ even nowadays when we can use excellent diagnostic methods. Therefore, many breast surgeons in Europe, America and Japan tend to select mastectomy as a local therapy for noninvasive breast carcinoma $^{7}$, and most of them would only inform the patient of BCT and mastectomy as alternatives.

Multicentricity ${ }^{1 \sim 4)}$ is another important pathologic risk factor in BCT. It has been pointed out that lobular carcinoma develops in a multicentric manner more often than ductal carcinoma does. In this study, we could not assess the usefullness of nipple-preserving total glandectomy for lobular carcinoma in situ because there were only two such patients enrolled. However, we think nipple-preserving total glandectomy should be safe and effective for lobular carcinoma in situ, because we have already reported the usefullness of this procedure for invasive lobular carcinoma ${ }^{18)}$.

In our present series, we did not pathologically examine the whole mammary gland, except in T0 patients with bloody nipple discharge. More intensive and precise pathological examination might have exposed the presence of a microinvasive component in some cases. Nevertheless, if axillary dissection is added ${ }^{20)}$, nipple-preserving total glandectomy is safe for patients having a microinvasive component. On the other hand, if so-called "probe lumpectomy ${ }^{21 \text { ") }}$ is performed as a routine, breast 


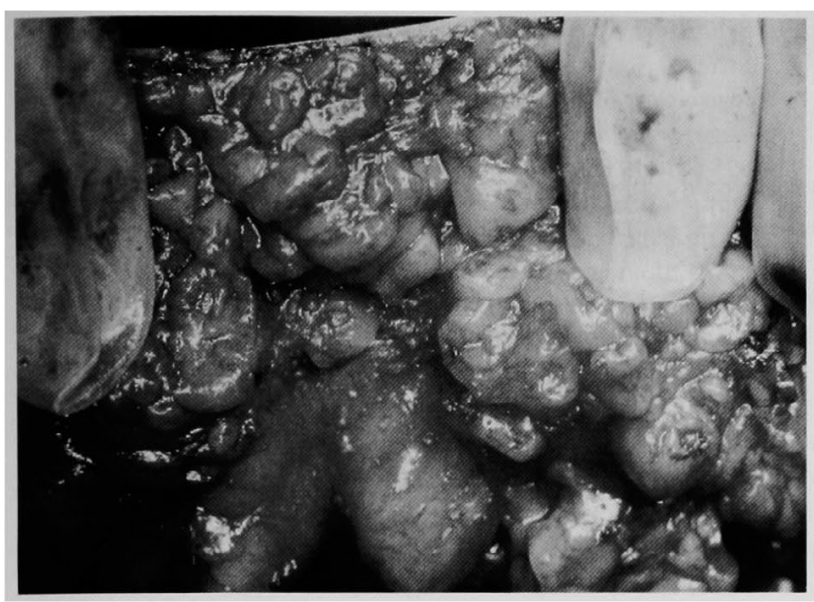

Fig. 1 Possible removal of subnipple mammary gland There is little mammary gland beneath the nipple after nipple base resection.

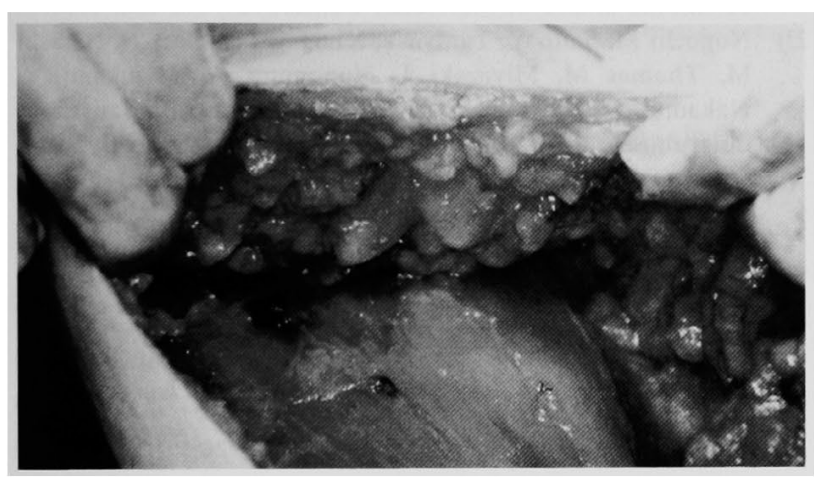

Fig. 2 Thick skin flap technique

Subcutaneous fat tissue is preserved as much as possible, especially in the negiborhood of the nipple.

surgeons will be able to omit axillary dissection for many patients with real noninvasive breast carcinoma and apply BCT in some cases with less EIC.

None of our patients needed to undergo additional nipple resection due to cancer infiltration in the nipple base. As the margin-positive rate at the nipple base was about $5 \%$ in our series of invasive breast carcinomas, the margin-positive rate was lower in our noninvasive breast carcinoma patients. We could not assess actual cancer spread within the mammary gland in this study, because we made whole mammary gland sections only in T0 breast carcinoma with bloody nipple discharge. Furthermore, our study had a bias in that all tumors were non-comedo type noninvasive ductal carcinoma.

Therefore, the low margin-positive rate in our series might have resulted from the fact that these tumors show less spread in the mammary gland. Nevertheless, it is possible that the low margin-positivity was not due to selection bias but to our technique ${ }^{201}$ of nipple base resection (Fig. 1) for the following reasons: First, we operated on all 16 noninvasive cases after 1985 with nipple-preserving total glandectomy or breast-conserving surgery. Second, comedo type noninvasive carcinoma usually has less spread in the mammary gland than the papillary type ${ }^{22)}$. However, it is well known that noninvasive ductal carcinoma generally has more extension in the mammary gland than invasive ductal carcinoma. Therefore, the margin-positive rate may raise to that for invasive breast carcinoma when more cases are assessed in the future.

Many patients treated with nipple-preserving total glandectomy without breast reconstruction have a poor cosmetic outcome. However, some show a good cosmetic outcome only with nipple-preserving total glandectomy, especially in those with small breasts. On the other hand, we should be able to perfrom immediate breast reconstruction using musculo-cutaneous or musculo-fat flap techniques ${ }^{23)}$ without hesitation because of the low risk of local recurrence. Furtheremore, if breast surgeons operate on noninvasive breast carcinoma using our thick flap technique $^{20)}$ (Fig. 2), the cosmetic outcome will be better in many cases.

In conclusion, breast surgeons should initially aim to treat noninvasive breast carcinoma with BCT, and secondly use salvage nipple-preserving total glandectomy with or without breast reconstruction rather than mastectomy.

\section{References}

1) Stegner H E. Pathology of malignant diseases of the breast. In : Strombeck JO, Rosato FE, eds. Surgery of the breast. New York; Thieme Inc. 66-74, 1986.

2) Bassett LW, Jahanshahi R, Gold RH, Fu YS. Film-screen mammography. London; Martin Dunitz Co. 233-240, 1991.

3) Haagensen CD, Bodian $C$, Haagensen DE. Lobular neoplasm (Lobular carcinoma in situ). In : Breast carcinoma. Philadelphia; WB Saunders Co. 238-282, 1981.

4) Posner MC, Wolmark N. Non-invasive breast carcinoma Breast Cancer Res Treat, 21 : 155-164, 1992.

5) Tsunoda $\mathrm{H}$, Ueno E, Tohno E, Akisada M. Echography of ductal spread of breast carcinoma. Jpn J Med Ultrasonics, 17 : 44-49, 1990 (in Japanese)

6) Kamio T, Kameoka S, Kimura T, Hamano K. Ultrasonographic diagnosis of intraductal spread of breast cancer: Study on impalpable breast cancer. Jpn J Breast Cancer, $6:$ 455-463, 1991 (in Japanese).

7) Silverstein MJ, Gierson ED, Colburn WJ. Cope LM, Furmanski M, Senofsky GM. Gamagami P, Waisman JR. Can intraductal breast carcinoma be excised completely by local excision? Cancer, 73 : 2985-2989, 1994.

8) Hart M, Economou SG. Breast-sparing surgery for cancer. In Economou SG, Witt TR, Deziel DJ, Saclarides TJ, Staren ED, Bines SD eds.; Adjuncts to cancer surgery, Philadelphia Lea \& Febiger Co. 267-272, 1991

9) Japanese Breast Cancer Society. General rules for clinical and pathological recording of breast cancer. The 11 th ed.: 2-3. 1992.

10) Holland R, Connolly JL, Gelman R, Mravunac M, Hendriks J, Verbeek A, Schnitt SJ, Silver B, Boyages J, Harris JR. The 
presence of an extensive intraductal component following a limited excision correlates with prominent residual disease in the remainder of the breast. Journal of Clinical Oncology, 8 : 113-118, 1990.

11) Boyages J, Recht A, Connolly JL, Schnitt SJ, Gelman R, Kooy H, Love S, Osteen RT, Cady B, Silver B, Harris JR. Early breast cancer; predictors of breast recurrence for patients treated with conservative surgery and radiation therapy. Raditother Oncol, $19: 29-41,1990$.

12) Kurz JM, Spitalier JM, Amalric R, Brandone H, Ayme Y, Bressac C, Hans D. Mammary recurrences in women younger than forty. I J Radiat Oncol Biol Phys, 15: 271-276, 1988.

13) Anscher MS, Jones P, Prosnitz LR, Blackstock W, Hebert M, Reddick R, Tucker A, Dodge R, Leight G, Iglehart JD, Rosenman $J$. Local failure and margin status in early-stage breast carcinoma treated with conservation surgery and radiation therapy. Ann Surg, $218: 22-28,1993$.

14) Wazner DE, Sinesi $M$, Schmidt-Ullrich $\mathbf{R}$, Smith TJ, Safaii $\mathbf{H}$, Marchant DJ, Homer MJ, Robert NJ. Importance of surgical and pathologic determinants of tumor margin status for breast conservation therapy. Breast Dis, $4: 285-292,1991$.

15) Jacquemier J, Kurz JM, Amalric R, Brandone $H$, Ayme $Y$, Spitalier JM. An assessment of extensive intraductal component as a risk factor for local recurrence after breast-conserving therapy. Br J Cancer, 61 : 873-876, 1990.

16) Krishnan L, Jewell WR, Krishnan EC, Cherian R, Lin F. Breast cancer with extensive intraductal component: Treatment with immediate interstitial boost irradiation. Radiology, 183 : 273-276, 1992.
17) Schnitt SJ, Connolly JL, Khettry U, Mazoujian G, Brenner M, Silver B, Recht A, Beadle G, Harris JR. Pathologic findings on re-excision of the primary site in breast cancer patients considered for treatment by primary radiation therapy. Cancer, 59 : 675-681, 1987.

18) Oura S, Sakurai T, Yosimura G, Tamaki T, Umemura T. Significance of nipple-preserving total glandectomy in relation to histological type. J Jpn Soc Clin Surg, 56 : 486-492, 1995 (in Japanese).

19) Oura S, Sakurai T, Yosimura G, Tamaki T, Umemura T, Naito $Y$, Suzuma T. Nipple-preserving mastectomy (Glt + Ax) as a standard operation for p-stage 1,2 breast cancer. J Jpn Surg Soc, 95 : 887-892, 1994 (in Japanese).

20) Oura S, Sakurai T, Yoshimura G, Tamaki T, Umemura T, Kokawa $Y$. Usefulness of the thick flap technique in nipple base resection for breast cancer patients. J Jpn Soc Cancer Ther, 30: 1828-1834, 1995 (in Japanese).

21) Akiyama $F$, Sakamoto $G$, Iwase $T$, Nakamura $H$, Ueno $M$, Yosimoto M, Watanabe S, Kasumi F, Sugano H. Probe lumpectomy-A new trial of breast conservative therapy. Jpn J Breast Cancer, 8 : 409-414, 1993.

22) Lennington WJ, Jensen RA, Dalton LW, Page DL. Ductal carcinoma in situ of the breast. Cancer, 73: 118-124, 1994.

23) Noguchi M, Saito $Y$, Taniya $T$, Kitagawa $H$, Ohta N, Earashi M. Thomas M, Miyazaki I, Nonomura A, Mizukami Y, Nakamura S, Michigishi T. Wide resection with latissimus dorsi muscle transposition in breast-conserving surgery. Surg Oncol, 1 : 231-236, 1992. 